\title{
Notas sobre o Neo-Realismo português: um desejo de transformação
}

\author{
IZABel Margato ${ }^{1}$ \\ (Pontifícia Universidade Católica do Rio de Janeiro)
}

\begin{abstract}
RESUMO: IDENTIFICAÇÃO DOS TRAÇOS QUE PARTICULARIZAM O NEO-REALISMO PORTUGUÊS A PARTIR DE TRÊS MOVIMENTOS (NOTAS). O PRIMEIRO MOVIMENTO BUSCA LOCALIZAR E DELIMITAR O MOVIMENTO NO PERÍODO COMPREENDIDO ENTRE O FINAL DOS ANOS 30 E AS DÉCADAS DE 40 E 50 EM PORTUGAL. O SEGUNDO RECUPERA DADOS DA POLÊMICA PERMANENTE QUE ENVOLVEU OS ARTISTAS E ESCRITORES NEO-REALISTAS, PRIORIZANDO A FOCALIZAÇÃO DA POLÊMICA INTERNA, TRAVADA EM TORNO DA ASSERTIVA "A REDUÇÃO DO ARTíSTICO AO IDEOLÓGICO", COMO UM LUGAR-COMUM CONSTANTEMENTE ATRIBUÍDO ÀS PRODUÇÕES E PROPOSTAS DO NEO-REALISMO. O TERCEIRO MOVIMENTO VOLTA-SE PARA A QUESTÃO DO PESO POLÍTICO ATRIBUÍDO AO TRABALHO COM A LINGUAGEM.
\end{abstract}

ABSTRACT: THIS ESSAY IDENTIFIES THE PARTICULAR TRACES OF THE PORTUGUESE NEOREALISM BASED ON THREE MOVEMENTS (NOTES). THE FIRST MOVEMENT TRIES TO SPOT AND SET THIS AESTHETIC MOVEMENT LIMITS WITHIN THE LATE 1930'S AND THE OF 1940'S AND 1950'S IN PORTUGAL. THE SECOND ONE RETRIEVES DATA ABOUT THE PERMANENT INTERNAL POLEMIC AROUND THE "REDUCTION OF THE ARTISTIC TO THE IDEOLOGICAL", AS A COMMON SENSE CONSTANTLY ATTRIBUTED TO THE NEO-REALISTIC PRODUCTIONS AND PROPOSALS. THE THIRD MOVEMENT FOCUSES ON THE POLITICAL RELEVANCE ATTRIBUTED TO THE LANGUAGE WORK.

PALAVRAS-CHAVE: NEO-REALISMO PORTUGUÊS - LITERATURA E POLÍTICA - LITERATURA PORTUGUESA DO SÉCULO XX.

KEY-WORDS: PORTUGUESE NEO-REALISM - LITERATURE AND POLITICS - $20^{\text {TH }}$ CENTURY PORTUGUESE LITERATURE.

1 PUC-Rio - Departamento de Letras. Cátedra Pe. Antonio Vieira de Estudos Portugueses. CNPq. 


\section{ara António Pedro Pita}

Além do desdobramento que este título encerra, proponho três tópicos, ou três notas, para pensar o movimento que durante mais ou menos vinte anos polarizou a cena cultural e política da sociedade portuguesa na primeira metade do século XX. O primeiro destes tópicos diz respeito à definição ou delimitação do próprio movimento. Poderíamos dizer que o Neo-Realismo português surge como uma movimentação cultural ao longo dos anos 30 e se consolida nos anos 40, paralelamente à consolidação do Estado Novo Português. Talvez seja importante neste momento a recuperação de três datas, três momentos de virada no conturbado cenário político da sociedade portuguesa desse início de século: o ano de 1910 marca o triunfo da revolução lisboeta, o chamado "5 de outubro", que em meio à "crise terminal da monarquia" (ROSAS, 2004: 28) implanta o regime republicano em Portugal. 1926 vai assinalar a data do "golpe militar fundador da ditadura [...] que substitui a $1^{a}$ República demoliberal e a partir do qual se estruturará o Estado Novo" (RODRIGUES, 2000: 307) em 1933. Três datas, portanto, em um curto espaço de tempo marcam o cenário conturbado e adverso em que um grupo de jovens (PITA, 2008) (na verdade muito jovens: eram rapazes que andavam pelos dezessete ou dezoito anos) iniciava um movimento de aproximação, de encontros sem motivação aparente: "Nós fomos ao encontro uns dos outros pelos nossos pés”, disse Mário Dionísio (PITA, 2008). No entanto, apesar de muito jovens, os componentes desse grupo já possuíam afinidades suficientes - expectativas acima de tudo - para dar forma ao desejo comum de constituir um amplo movimento cultural que também se traduzisse em prática de resistência à ditadura do Estado Novo. Esse duplo movimento está na origem do NeoRealismo Português. Como também está a orientação marxista que vai enformar diferentes manifestações do grupo e fornecer as bases para uma nova visão de mundo, "uma visão alternativa" (PITA, 2008) à ideologia com que o Estado Novo impunha a sua visão totalizadora, que a todos impregnava, como "uma sintaxe do pensamento", isto é, como "uma autêntica profilaxia de Estado que não visava apenas controlar mas, principalmente, criar formas de mentalidade adaptadas ao Poder" (CARDOSO PIRES, 1977:199-200).

Essa visão alternativa de mundo que se ensaiava no final dos anos $30 \mathrm{em}$ Portugal só poderia ser vista com muitas expectativas, e com muitas oposições também. Para António Pedro Pita, "nenhuma movimentação, ao longo 
do século XX português, foi acompanhada de tantos investimentos, tantas expectativas e tantas incompreensões como a do Neo-realismo" (PITA, 2008). Para o ensaísta, muitas das expectativas suscitadas pelo movimento estão na base de uma série de incompreensões e equívocos que vão envolver o NeoRealismo em um estado de "permanente polêmica" (PITA, 1999).

$\mathrm{O}$ viver em estado de permanente polêmica é a segunda nota que dá corpo a este texto. Trata-se de um lugar-comum, de referência obrigatória, incontornável até, poderíamos dizer. O espaço deste texto não nos permite dar uma visão ampla e aprofundada desse traço que acompanhou e ultrapassou o movimento. Entretanto, talvez seja possível fazer uma ou duas aproximações. Com a primeira, poderíamos destacar dois pontos polêmicos: o primeiro aponta para uma orientação teórico metodológica, que supõe um movimento convergente entre "teoria, prática e poesia ao mesmo tempo" (PITA, 2008). Esse pressuposto, segundo António Pedro Pita, nasce da suposição de que cada uma dessas esferas se interliga e se superpõe, o que provocou não apenas polêmicas, mas deu origem a muitos equívocos. O segundo ponto controverso pode ser identificado como o grande responsável pela acirrada polêmica neo-realista. Ele tem a sua origem em uma orientação (ou interpretação) de que a obra de arte deveria ter "um papel efetivamente atuante do ponto de vista político-social" (MARTELO, 2004). Essa orientação, desdobrada em diferentes textos e em diferentes tons, em pouco tempo incorporou expressões como: "critério essencialmente pragmático para a apreciação das obras de arte"; "primado do conteúdo sobre a forma"; "comunicabilidade direta da obra de arte", o que acabou por traduzir-se na fórmula-síntese "a redução do artístico ao ideológico", que durante os anos dessa polêmica - e também depois deles - ficou associada ao Neo-Realismo como um todo. A conseqüência imediata da adoção desse pressuposto traduz-se na identificação dos textos neo-realistas como produções de um realismo inferior, que devem ser lidos, prioritariamente, como documentos de época. Acrescentando mais um dado, poderíamos dizer que grande parte da demarcação a que a produção neo-realista ficou sujeita deve-se, principalmente, a um posicionamento crítico redutor que considera essas obras apenas como documentos políticos decalcados da e pela ideologia marxista.

A famosa e linear assertiva: "a redução do artístico ao ideológico", usada para definir as obras neo-realistas, é o grande argumento escolhido por todos aqueles que se colocam em posição de reserva, ou mesmo de firme oposição, ao 
movimento. Mais precisamente, essa assertiva foi o grande fantasma com que tiveram que se debater todos aqueles que aceitaram a súbita exigência de produzir arte e, ao mesmo tempo, centrar o seu interesse no estudo da sociedade. Este é, enfim, o grande lugar-comum que polariza, interna e externamente, a polêmica em torno da arte neo-realista.

Quando nos aproximamos um pouco mais dos textos que traduzem esses dois movimentos da polêmica (o interno e o externo), percebemos que, apesar de variadas, as manifestações externas em torno desse tópico são quase sempre redundantes, já que os seus resultados não costumam ir muito além de uma recusa cerrada e sistemática. Internamente, entretanto, a polêmica gerada por esse pressuposto redutor se desenvolveu de forma mais produtiva por encaminhar diferentes propostas e apontar para a importância do trabalho com a linguagem na produção das obras literárias. Segundo a crítica mais recente, esta posição gradativamente ganha corpo, transformando-se a seguir numa questão teoricamente mais consistente: a de se "saber se a linguagem é ela própria uma questão política" (PITA, 2008). Ultrapassado o primeiro momento mais conturbado, esta tomada de posição funciona como um divisor de águas, um limite intransponível que vai "rachar" o então "núcleo duro" do neo-realismo português.

No texto "Do compromisso à aporia", Rosa Maria Martelo faz o mapeamento de muitos momentos dessa divisão. Num deles, a autora recupera trechos de textos fundamentais para se perceber as diferentes posições dos poetas neo-realistas diante da proposta de um livro "circunstancial, intervencionista" que se constituísse "em um canto de esperança [...] que o materialismo histórico permitiria esboçar como uma certeza de contorno bastante definido" (MARTELO, 2004: 53).

Este modelo, que facilmente se deduz das reflexões teorizantes de figuras como Jofre Amaral Nogueira, Rodrigo Soares, António Ramos de Almeida, Mário Ramos, ou mesmo Álvaro Cunhal, tinha, no entanto, implicações de outra ordem, e por isso mesmo, para os poetas a questão não se limitava aos conteúdos nem às opções ideológicas. A questão essencial era como escrever. "Como?” - é a pergunta que Mário Dionísio contrapõe reiteradamente à exaltação nascida do sonho de uma sociedade nova [...]. (MARTELO, 2004: 53) 
No artigo de 1954 "O Sonho e as Mãos”, citado pela ensaísta, Mario Dionísio desenvolve essa inquietação:

Como transpor para uma página, para uma tela essa vida que vivemos e que nos pedem reconhecível e eficiente? Como tornar este ou aquele fato, este ou aquele sentimento artisticamente denso de significado? (DIONÍSIO, 1954: 98)

Rosa Maria Martelo chama a atenção para o fato de que, já em 1939, o poeta expressava a sua resistência em um artigo publicado no jornal O Diabo, cujo título não poderia ser mais sugestivo: "S.O.S Geração em Perigo":

Nunca alguém disse que queria uma arte panfletária. Nunca alguém disse que se pretende impor ao artista estes ou aqueles temas e proibir-lhes outros. (DIONíSIO, 1939)

Apenas para complementar com mais um registro a polêmica interna travada em torno da "redução do artístico ao ideológico", recupero mais um pronunciamento analisado pela ensaísta:

Carlos de Oliveira exprimia idêntico ponto de vista, ao responsabilizar pela falta de um tom nacional na literatura portuguesa certa teorização que postulava levianamente o desprezo da forma, exigindo sobretudo de cada romance e de cada poesia, que gritasse verdades como punhos. Mas acontece que uma obra de arte não o será sem qualidade artística; acontece que a beleza exige um permanente estado de equilíbrio entre as verdades que se dizem e as palavras que as dizem. (MARTELO, 2004: 55)

A tematização da linguagem se aprofunda e diversifica, quando trazida para a cena do poema, como se pode ver na primeira parte do poema "Coração", de Carlos de Oliveira, onde a palavra ganha uma força e uma precisão até então desconhecidas

\footnotetext{
Tosca e rude poesia, meus versos plebeus são corações fechados,
} 
trágico peso de palavras

como um descer da noite

aos descampados.

Ó noite ocidental,

Que outra voz nos consente

A solidão?

Cingidos de desprezo,

somos os humilhados

cristos desta paixão.

E quanto mais nos gelar a frialdade

dos teus inúteis astros,

mortos de marfim,

mais e mais, gênio do povo,

tu cantarás em mim.

(OLIVEIRA, 1992: 41)²

Ou ainda, o poema 4, do livro Mãe Pobre, onde o poeta constrói, com a máxima justeza e rigor, a singularíssima representação da "concretude" das palavras:

Aço na forja dos dicionários,

as palavras são feitas de aspereza;

o primeiro vestígio da beleza

é a cólera dos versos necessários. ${ }^{3}$

É essa a vertente que mais nos interessa. É este o lado produtivo do debate em torno da questão da linguagem; isto é, a de saber, como já foi apontado, se ela poderia constituir-se em um fato ao mesmo tempo artístico, político e revolucionário.

Dentro dessa linha, do lado produtivo do debate internamente travado, poderíamos dizer que a vertente teórica a que se ligam Carlos de Oliveira, João

2 Primeira parte do poema "Coração" (OLIVEIRA, 1992a: 41).

3 Poema 4 de "Odes" (OLIVEIRA, 1992a: 56). 
José Cochofel, Joaquim Namorado e Mário Dionísio deu origem a proposições estéticas inovadoras sobre a nova arte realista. Para efeito de demonstração, destaco um recorte do texto "A propósito de Jorge Amado", publicado no jornal O Diabo que, ao lado da revista Vértice, se transformou num dos veículos mais relevantes para o mapeamento da produtiva polêmica interna que vai definir de forma decisiva os pressupostos e a orientação estética do Neo-Realismo.

Advogamos para toda a obra de arte uma estrutura realista, e o [...] real para nós não é também unicamente o palpável mas o que ainda não é, mas será. Vem a propósito citar a opinião de Marcel Gromaire: "o real não é somente o que é do domínio de nossa mão, do domínio da nossa vista, é também o que é do domínio do nosso espírito e o que ainda não é do domínio do nosso espírito." (DIONÍSIO, 1937)

A partir destas percepções mais elaboradas e mais amplas do conceito de real, esses autores lidam de outra forma com o resistente fantasma da redução do artístico ao ideológico, na medida em que desdobram e reelaboram o conceito de realismo, a partir de novas configurações e de uma concepção de arte onde o real passa a ser muito mais "visado" do que "representado", ou "reproduzido" (DELEUZE, 2005).

Visivelmente contrários à noção de referencialidade modelada pela tradição realista, estes escritores desencadearam, com seus textos, a desmontagem da articulação muitas vezes mimética entre texto e realidade de algumas proposições do movimento, ao mesmo tempo em que promoveram a "transferência do debate em torno do neo-realismo do campo estritamente ideológico para os da estética e da poética." (MARTELO, 1999). A partir da retomada de formulações teóricas que reinterpretam a noção de mimese e dão outro entendimento aos mecanismos de referencialidade, surgem, então, as novas produções neo-realistas, nas quais a concepção de arte nasce de um processo que articula diferentes procedimentos formais a uma "mediação irredutível", capaz de "processar reconstruções de mundo" e de revelar "o que ainda não é da ordem do visivel' (PITA, 1999).

Buscando completar a proposta anunciada, passo ao terceiro tópico deste texto, ou seja, à última nota que escolhi para aproximar-me do movimento cultural com que artistas e intelectuais portugueses puseram em cena aberta 
o verdadeiro corpo social do país. Para ler mais de perto essa cena, recorro a um conjunto de textos poéticos de Carlos de Oliveira que (embora aqui recortados e fragmentados) ecoam como sinais de uma "vigília longa e desumana", vivida e dramatizada nos versos do poema "A noite inquieta":

Só, em meu quarto, escrevo à luz do olvido;

deixai que escreva pela noite dentro:

sou um pouco de dia anoitecido

mas sou convosco a treva florescendo.

Por abismos de mitos e descrenças

venho de longe, nem eu sei de aonde:

sou a alegria humana que se esconde

num bicho de fábulas e crenças.

Deixai que conte pela noite fora

como a vigília é longa e desumana:

doira-me os versos já a luz da aurora, terra da nova pátria que nos chama.

Nunca o fogo dos fáscios nos cegou

e esta própria tristeza não é minha:

fi-la das lágrimas que Portugal chorou

para fazer maior a luz que se avizinha.

$[\ldots]^{4}$

Desse longo recorte, destaco a imagem da noite nos diferentes sentidos em que é trabalhada pelo poeta. Num sentido mais imediato, noite tem como dado referencial o período de tempo destinado ao sono e ao descanso. Entretanto, a noite, neste poema, é marcada pela vigília "longa e desumana" do poeta que escreve entre sentidos desencontrados e imagens desconexas de uma noite que se sustém, há muitos anos, em "abismos de mitos e descrenças". E agora sim, passamos ao segundo sentido da palavra "noite", isto é, a mais evidente metáfora do

4 "A noite inquieta". Colheita Perdida (OLIVEIRA, 1992b: 83). 
fascismo. Essa metáfora é bastante recorrente não só nos versos de Carlos de Oliveira ("Canta na noite, sentimento da terra, / ou morreste, flor estranha?"5; Hei-de cantar-vos a beleza um dia, / quando a luz que não nego abrir o escuro / da noite que nos cerca como um muro, / e chegares a teus reinos, alegria." ${ }^{6}$ ), como também na produção de outros poetas neo-realistas. Trata-se de uma imagem cifrada que aos poucos foi-se tornando conhecida e evidente demais. $\mathrm{E}$ é este o momento de se destacar o mecanismo rigoroso através do qual o poeta revitaliza a metáfora gasta. Dois versos da primeira estrofe do poema "A noite inquieta" já dão conta da genialidade desse processo: "sou um pouco de dia anoitecido / mas sou convosco a treva florescendo." O sintagma "dia anoitecido" supera em muito o sentido sugestivo de "noite" para metaforizar o fascismo; do mesmo modo que "treva florescendo" revitaliza e amplia os sentidos que a palavra manhã continha até então.

Com os versos de Carlos de Oliveira também aprendemos que a grande metáfora da liberdade (ou da revolução) estará sempre ligada à dupla face do "sentimento da terra" que, ao mesmo tempo, o anima e inquieta:

Canta na noite, sentimento da terra,

Ou morreste, flor estranha?

Há tanto já que chove e nós sem lenha,

Sem paz e sem guerra.

Há tanto. E eu sei lá bem

se inda persistes,

minha incólume esperança.

Vão-me doendo os olhos já de serem tristes.

Vão-me doendo,

Que mos turva de sombra o desespero.

E escrevendo à luz débil me pergunto

se é a morte ou a manhã que espero. ${ }^{7}$

5 Poema 4 de "Coração". Mãe Pobre (OLIVEIRA, 1992b: 44).

6 "Soneto". Mãe pobre (OLIVEIRA, 1992b: 58).

7 Poema 4 de "Coração". Mãe pobre (OLIVEIRA, 1992b: 44). 
O evidente diálogo estabelecido com a tradição da lírica portuguesa e a reverberação de antigas imagens ("Vão-me doendo os olhos...") atualizam, no corpo do poema, uma consciência do "valor histórico e coletivo das palavras" (GUSMÃO, 1981: 28) que, como antigas sementes guardadas em celeiros, são capazes de conter e fazer reverberar o "sentimento da terra". Por outro lado, mas com igual intensidade, a repetição insistente da expressão "Há tanto" envolve o canto numa espécie de desânimo, ou numa inquietação desesperada que põe em dúvida a permanência dessa flor estranha, matricial e coletiva.

Poder-se-ia dizer, na esteira de Manuel Gusmão, que a interrogação ao "sentimento da terra" - esse celeiro primordial - vai formar uma das "zonas lexicais dominantes” (GUSMÃO, 1981: 28) da poesia de Carlos de Oliveira. Além do sentido primeiro capaz de retomar a tradição lírica do povo português, ou ainda, de evocar os extratos lexicais apropriados para revelar a "voz do povo", creio que "sentimento da terra" tem na poesia de Carlos de Oliveira o sentido de um reservatório de resistência - moral ou histórico, tanto faz -; um núcleo familiar, coletivo (por algum tempo perdido) a que o poeta insistentemente retorna e busca recuperar. Esse sentimento necessário também pode ser descrito como um "sentido de realidade" que marca na raiz a poesia do autor.

Para nos aproximarmos mais desse sentido amplo que identificamos na expressão "sentimento da terra", recorro aos seis poemas que compõem a primeira parte do livro Turismo, ${ }^{8}$ de Carlos de Oliveira. São eles que abrem a primeira parte da nova versão desse livro que, em 1976, reaparece totalmente refundido por uma escrita marcada pelo rigor e pela concisão. Mais precisamente, são eles que abrem o Trabalho poético do autor, o que lhes dá um valor emblemático, matricial.

Escolho esses pequenos poemas por acreditar que eles também podem ser lidos como uma Arte Poética, ou melhor, como uma forma de "teorização" em versos, de um trabalho poético que se apresenta no próprio corpo do poema.

8 Este livro que foi publicado em 1942, na coleção "Novo Cancioneiro", desaparece na edição de Poesia (1962) onde o autor reuniu a sua produção poética até aquela data, para reaparecer (refundido) em 1976, em nova recolha, agora sob o título Trabalho poético. 
Infância

I

Terra

sem uma gota

de céu.

II

Tão pequenas

a infância, a terra.

Com tão pouco

mistério.

Chamo às estrelas

rosas.

E a terra, a infância,

crescem

no seu jardim

aéreo.

III

Transmutação

do sol em oiro.

Cai em gotas,

das folhas,

a manhã deslumbrada.

IV

Chamo

a cada ramo

de árvore

uma asa.

$\mathrm{E}$ as árvores voam.

Mas tornam-se mais fundas

as raízes da casa, 
mais densa

a terra sobre a infância.

É o outro lado

da magia.

V

E a nuvem

no céu há tantas horas,

água suspensa

porque eu quis,

desmorona-se e cai.

Caem com ela

as árvores voadoras.

VI

Céu

sem uma gota

de terra.

Os poemas aqui transcritos estão agrupados sob o título Infância. Eles articulam três movimentos que se completam e se interligam da seguinte maneira: o primeiro parece ligar-se ao mundo da infância, ou das circunstâncias mais prosaicas e cotidianas, onde a interferência da poesia não se faz presente. Trata-se de um mundo sem nenhuma transcendência, sem sonho, ou se preferir, sem poesia. O segundo movimento traz-nos o mundo marcado e demarcado pela ação do poeta. É ele o agente capaz de transformar o mundo anterior da infância em um espaço etéreo, misterioso, em que (pela ação poética) é possível a "Transmutação do sol em oiro", porque ato poético da nomeação recupera a força adâmica da linguagem: Chamo às estrelas / rosas. / E a terra, a infância, / crescem / no seu jardim / aéreo.

9 "Infância". Turismo (OLIVEIRA, 1992b: 17-22). 
O terceiro movimento é aquele em que a poesia se une ao mundo, criando, por uma espécie de "nova magia", uma "realidade nova". O quarto poema é o ápice deste momento. Nele, duas forças se comprimem e se ajustam: Se por um lado, se reafirma a força adâmica do poeta, por outro, a comunhão com o "sentimento da terra" se estabelece, como "o lado da magia". Trata-se de uma sofisticada representação do caminho poético escolhido pelo autor, onde o rigor, a concisão e a justeza de cada palavra não eliminam o diálogo necessário com os sentimentos do mundo.

Nesse sentido, os três movimentos modulados pelos seis poemas articulam um trabalho poético, retomando núcleos e reproduzindo muitas das questões que permearam a trajetória desses jovens escritores que, gradativamente, souberam escrever uma página nova no grande livro das Artes Portuguesas, sem deixar de posicionar-se como intelectuais comprometidos com uma prática de resistência ao fascismo. Gostaria ainda de reafirmar que estes seis pequenos poemas recuperam, de alguma maneira, uma orientação teórica do movimento, que destaquei no início deste texto. Trata-se da proposição que torna possível a "convergência entre teoria, prática e poesia ao mesmo tempo" (PITA, 2008).

\section{Referências Bibliográficas}

CARDOSO PIRES, José. Técnica do golpe e censura. In: E agora, José?. Lisboa: Moraes, 1977.

DELEUZE, Gilles. A imagem-tempo. São Paulo: Brasiliense, 2005.

DIONÍSIO, Mário. A propósito de Jorge Amado. O Diabo, n. 164, 14 jan. 1937.

. S.O.S. Geração em Perigo. O Diabo, 24 jun. 1939.

. O Sonho e as Mãos. Vértice, XIV, n. 125, fev. 1954.

GUSMÃO, Manuel. Apresentação crítica. A poesia de Carlos de Oliveira. Lisboa: Seara Nova, Editorial Comunicação, 1981.

MARTELO, Rosa Maria. Oscar Lopes em 'A Crítica do Livro'. In: Encontro Neo-Realismo - reflexões sobre um movimento - perspectivas para um museu. Vila Franca de Xira: Edição do Museu do Neo-Realismo/Câmara Municipal de Vila Franca de Xira, 1999. 2004.

Do compromisso à aporia. In: Em parte incerta. Porto: Campo das Letras,

Em parte incerta. Porto: Campo das Letras, 2004.

OLIVEIRA, Carlos. Mãe pobre. Lisboa: Caminho, 1992a. 
. Trabalho poético. Lisboa: Caminho, 1992b.

PITA, António Pedro. A árvore e o espelho - Elementos para a interpretação da heterogeneidade neo-realista. In: Encontro Neo-Realismo - reflexões sobre um movimento - perspectivas para um museu. Vila Franca de Xira: Edição do Museu do Neo-Realismo/Câmara Municipal de Vila Franca de Xira, 1999.

Notas a partir do Curso: "Conflito e unidade no neo-realismo português", realizado na PUC-Rio, em maio de 2008.

RODRIGUES, António Simões. História de Portugal em datas. Lisboa: Temas e Debates, 2000.

ROSAS, Fernando. Pensamento e Acção Politica - Portugal Século XX (1890-1976). Lisboa: Editorial Notícias, 2004. 